\title{
Strengthening the link between theory and practice in teaching design engineering: an empirical study on a new approach
}

\author{
E. Tempelman • A. Pilot
}

Published online: 31 March 2010

(C) The Author(s) 2010. This article is published with open access at Springerlink.com

\begin{abstract}
In 2007, the Faculty of Industrial Design Engineering of the Delft University of Technology introduced a new bachelor program. Based on theories of learning and instruction three design principles were used to develop an approach that aims to make it easier for students to bridge the gap between theoretical design engineering courses and practical design projects. To investigate whether the new program is successful in this respect, we selected a representative combination of one course and one design project, analysed grades, sent out questionnaires and interviewed teaching staff. The unique change of all three course years at once, as opposed to sequential introduction, allowed us to establish a control group and obtain precise results. By repeating our studies 1 year later, we further enhanced the reliability of our findings. We conclude that our approach indeed strengthens the link between theory and practice, and have reason to be positive about the research method adopted. Furthermore, we identified several barriers that must be overcome for such an approach to become successful, and can now give additional recommendations for course and/or program revisions in teaching design engineering at academic level.
\end{abstract}

Keywords Constructivism · Course revision · Design engineering ·

Education · Program revision

\section{Introduction}

It may be true that "nothing is more practical than a good theory", but putting a good theory into practice is never easy. As noted by (Vincenti 1990) for design and engineering,

E. Tempelman $(\bowtie)$

Faculty of Industrial Design Engineering, Delft University of Technology,

Landbergstraat 15, 2628 CE Delft, The Netherlands

e-mail: e.tempelman@tudelft.nl

A. Pilot

IVLOS, Institute of Education, Utrecht University, Heidelberglaan 8,

3584 CC Utrecht, The Netherlands 
it usually takes considerable effort to bridge the gap between the two. Likewise, many design students struggle to use theoretical insights during their practical design assignments (Dym et al. 2005; Lutgens and Mulder 2002; Walter 2002). In particular, applying theory on design engineering turns out to be difficult for students, and all too often they fail to make the connection between theory and practice in this essential field (Tempelman et al. 2007; Van der Voort et al. 2008; van der Vegte et al. 2009). By 'design engineering', we mean the process of ensuring, through systematic analysis, simulation and testing, that a (product) design functions as intended and that it can be produced at acceptable cost (Roozenburg and Eekels 2005; Pahl et al. 2007).

A first promising solution to this problem is to interweave theory and practice much closer than before by offering assignments that are more authentic, i.e., more resembling real-life problems and the context related thereto (Pilot and Bulte 2006). Authenticity in assignments provides a meaningful context for students, enhances motivation, generates need-to-know and stimulates development of expertise in communities of (design) practice. In other words, a first program design principle is: provide an authentic context for design engineering.

Secondly, current insights in academic learning recommend teachers to distinguish explicitly between knowledge, skills and attitude, but also to consider the synthesis of these three elements in academic competences: these three together comprise what students need to learn, including the coherent structure and relations between knowledge and skills, strongly influenced by attitudes (Nedermeijer and Pilot 2000). The product design process provides a framework for the elaboration of this second program design principle, as the content of the courses has to be framed in this process of designing.

A third program design principle aiming at interweaving design theory and practice is related to the theory of constructivism, which assumes that all knowledge is constructed from previous knowledge (Cobb 1994; Bransford et al. 1999; Albers et al. 2004). A careful interweaving and sequencing of theoretical and practical elements can help students build elements of knowledge and skills onto each other and provide meaning for adding new elements to those they already acquired. In design education a long and enduring learning process should take place, relating elements of theory and practice in a way that is meaningful from the students' perspectives and carefully structured so they can construct meaningful wholes of knowledge, skills and attitudes. In other words, the third design principle focuses on a chain of activities and motives, stimulating and guiding students by authentic assignments and practicing activities to do something meaningful and realistic with the theory that is offered and enriching their understanding through reflection on their experiences in synthesising activities with theory in practice.

The synthesis of the three program design principles (context, content and chain of activities) yields a novel approach towards linking theory and practice in design engineering education. This approach is elaborated and described in more detail in the next two sections.

Based on these design principles, the Faculty of Industrial Design Engineering (or IDE for short) of the Delft University of Technology in 2007 introduced a new bachelor program (Bos et al. 2006; Roozenburg 2008). In this program, students still participate in theoretical courses and practical design projects as before, but the new program elements are oriented much more strongly at a synthesis of theory and practice, aiming to help students apply facts, theories and insights into their design projects. Assignments are more authentic in both subject and context, and 'standard' course elements are no longer used.

Does adoption of these principles indeed help to bridge the gap between theory and practice? That is the primary research question addressed here. We examined this for one 
practical design project, studying to what extent one preceding theoretical design engineering course prepared the students for it. In two consecutive years, we analysed grades, sent out student questionnaires and interviewed teaching staff. During the first year of our studies, $41 \%$ of the project's students had followed one or two of the comparable theoretical courses from the old bachelor program. We were therefore able to use them as a control group, comparing their results against those of the 59\% who took the new course. This allows a precise assessment of the new program's merits. One year later, we repeated the inquiry: this time, $82 \%$ took the new course.

The remainder of this paper is structured as follows. "The new IDE bachelor program and its development" provides an overview of the new IDE bachelor program and its development, while "Descriptions of the two program elements studied" presents the respective program elements in more detail (new as well as old ones). Sections from "Research method" to "Discussion" address the research method employed, the results obtained and the discussion thereof. The final section presents our conclusions regarding the primary research question, the wider applicability of our research method and lessons learnt for program revision.

\section{The new IDE bachelor program and its development}

It is fair to say that in the old IDE program, the theoretical courses and the practical design projects were worlds apart. Students learned, for instance, how to calculate the deflection of an idealised, cantilevered beam in bending during a course on structural analysis, but often did not apply this knowledge in the design of-say-a lightweight chair during a subsequent design project. As another example, they were told about the speed of production processes during a course on industrial production, but then failed to apply this knowledge to the projected production numbers while designing the same chair. Generally, students were only challenged to link theory to practice if their design project coach also happened to be involved in the theoretical courses.

In the vision on the new IDE bachelor program, this had to be changed. Linking theory to practice (and back) is not left to happenstance, but is now a cornerstone of the program as a whole. In the theoretical courses, problems are no longer presented in an abstract, easy-to-analyse form outright, but are given as realistically and authentically as possible instead. Students learn to 'translate' the problem into a simpler form that lends itself to analysis, as well as translate their answers back to real-world solutions (van der Vegte et al. 2010). To support this, the courses now comprise small projects also, in which students explicitly learn how to apply theory. Furthermore, a concurrent program of practical assignments has been set up, in which students learn how to measure e.g., the deflection of a chair during use, or make an excursion to a furniture assembly plant. These assignments enable students to discover abstract design engineering concepts, such as stiffness or production speed, through experience before learning how to formalise them. In the practical design projects, students are now explicitly challenged to base their design choices on theory and/or the outcomes of small experiments. Also, the involvement of experts in these projects has been intensified, who act not as 'oracles' but as sounding boards for the students (Christiaans and Venselaar 2005).

To make this possible, over $50 \%$ of the new program consists of active teaching formats (e.g., instruction sessions, practical work), against under $30 \%$ for its predecessor, in which the theoretical courses relied on plenary lectures with possibly a small side project. Per 
student, the new program requires a $\sim 25 \%$ more staff, but it also has an expected ${ }^{1}$ higher first-time pass rate, and ultimately increased efficiency.

Development of the new program started in September 2005 when a team of experts drew up the overall program and defined the outlines of each element. In June 2006, the coordinators were appointed and assigned the task of developing and introducing the respective courses and projects. This was an iterative process in which they all worked together intensively to ensure that elements connected to one another. In the 40 years of its existence, the IDE educational program has seen its share of revisions, but this last revision is the only time that all coordinators were actively involved. Buying in 'standard' theoretical courses from neighbouring faculties has stopped: e.g., all the necessary instructions in mathematics have now been integrated in the courses. In September 2007, the new program was introduced. Both authors were involved: the first as course coordinator and expert, the second as external consultant.

\section{Descriptions of the two program elements studied}

The first 2 years of the new program comprise twelve theoretical courses and four practical design projects. Each program element has a nominal study load of $210 \mathrm{~h}$, equally divided over a ten-week period, and students are expected ${ }^{2}$ to take part in two elements simultaneously. The elements studied here are further described below. The old comparable elements are also discussed briefly, as is the choice for studying these exact elements in the research presented here.

Industrial production (IP)

This design engineering course runs in the second quarter of the second study year. It concerns itself with the following three core questions:

- What are the possibilities and limitations of common production processes, as seen from a design perspective?

- How can designers gather relevant information on new production processes?

- During the design process, how can designers select the right production processes?

Compared to the old courses that dealt with this subject, Industrial production (IP) covers considerably fewer production processes, but it deals with them on a much deeper level, e.g., by giving explicit attention to the materials science underlying the processes. This content was already offered to them in a preceding course on design engineering, and IP therefore allows the students to build on previously-acquired competencies. Also, instead of giving design guidelines and rules-of-thumb, the course lets students actively derive such rules themselves from the underlying physics as well as from practical considerations. Regarding teaching modes, the course involves instruction sessions backed up by plenary lectures, plus a 42-h group project involving an excursion to a production plant and subsequent cooperation with industry (Tempelman et al. 2007; Tempelman and Spoormaker 2010). In this project, the students analyse a certain novel production process and then use

${ }^{1}$ Due to transitional effects, such as students trying to stay 'ahead of the revision', this key expectation can only be validated at a later stage.

2 The Dutch academic system allows for relatively large amounts of freedom, and in most engineering faculties, students who complete their studies in the nominal time are in fact a minority. 
their findings to design a new product that can be produced with it, with attention to function and aesthetics as well as manufacturability and cost price. A 16-h technical product analysis assignment, in which groups of students disassemble and analyse common products, completes the course. Crucially, all reports produced by the students are not 'graded and filed', but are (depending on quality) made available for use by other students in subsequent program elements. This strategy adds to the authenticity of the course.

Product design 4: embodiment and detail design (PO4)

This design project runs in the fourth quarter of the second study year. Its three core questions are:

- How can a product concept be elaborated into a detailed design?

- How can the properties of product details be predicted and validated?

- How can a detailed design be visualised, documented and communicated?

As their starting point, PO4 students receive a product concept (based on an existing patent), which they have to elaborate into a fully-detailed design. In doing so, they use and expand on competencies gained in essentially all of the preceding program elements, including IP. The work involves iterations (just as in professional design practice), during which the product evolves from concept to production-ready design. The students discover that they often need to go back to theory to solve their practical design problems, analyse existing product examples, call companies for information or even do small experiments to gather missing data. They work in teams of five students, who each elaborate several different components of their product. For an impression of the results, see Fig. 1. For the timing relative to IP, see Fig. 2.

Both program elements were first offered in the program year 2007-2008. In the following year, several minor adjustments were made to these elements (mainly involving

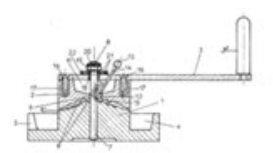

Hand operated flour mill Q 101010 Group 41 FWD
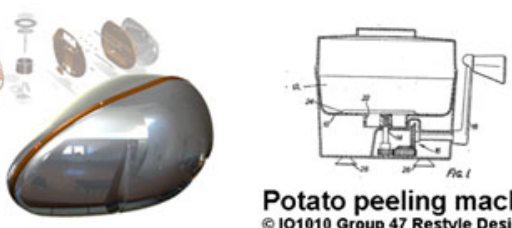

Potato peeling machine (101010 Group 47 Restyle Design

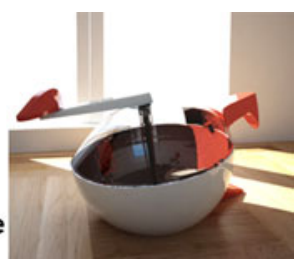

Fig. 1 Examples of PO4 work

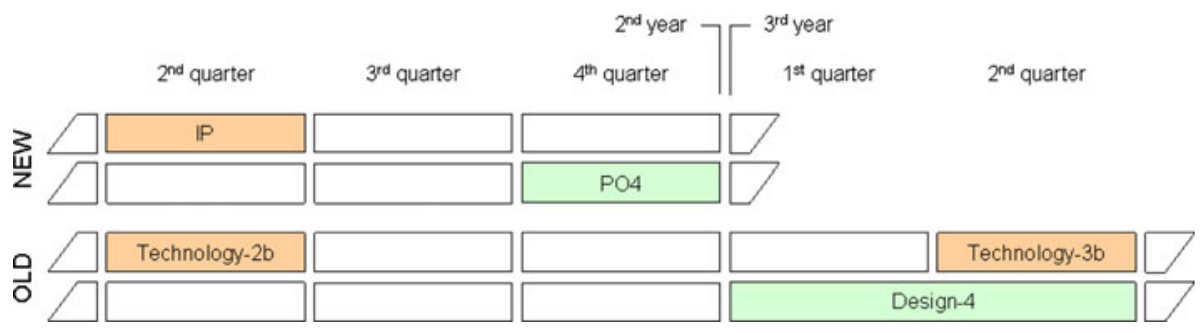

Fig. 2 Relative timing of courses (dark orange) and projects (light green), old and new BSc programs. (Color figure online) 
course logistics), but for the purposes of our research, both years can be assumed to be the same. The only significant exception was that in IP, the first experiences with PO4 led to increased and improved attention to one common production process. ${ }^{3}$

Comparable elements from the old program

The predecessor of PO4 as described above was the course 'Design-4'. It ran for a full semester and was therefore twice as long, also in terms of study load. However, it also included a conceptual design phase and a time-consuming prototyping phase; time spent on the actual embodiment design was comparable to that of PO4. Also, it combined individual and group work, just as the new project does. One key difference concerns timing: Design4 ran in the first half of the third study year, while PO4 runs in the final quarter of the second (see Fig. 2).

As a course element, IP has no single predecessor. Its content was split between 'Technology-2b' early in the second year (on production processes for parts and components) and 'Technology-3b' in the third year (on product assembly). This last course ran parallel to the second half of Design-4 (see Fig. 2). It offered students the option to select their Design-4 work as the subject for its two practical assignments on DFMA ${ }^{4}$ and on FMEA $^{4}$. The idea behind this parallel programming was to let students improve their designs with respect to manufacturability, reliability \& safety, and in general bridge the gap between theory and practice. However, this rarely led to design changes, contrary to what happens in actual industrial design practice. Together, the two old courses required a comparable study time as IP does today.

The choice for studying IP and PO4

In the first 2 years of the new program there are six (theoretical) design engineering courses and four (practical) design projects. Of all possibilities, the combination of IP and PO4 appeared as the logical choice for this study. PO4 runs immediately after the IP re-exams, guaranteeing that the maximum number of PO4 students has had a chance to master IP fully. Also, the theory offered in IP can be considered to be of average difficulty and complexity, making it a representative course from that respect, and to PO4 staff it is generally obvious if students can in fact apply this theory in their design. Finally, in study year 2007-2008 there was the benefit of having an 59-41\% split among the PO4 students between those who did and did not participate in IP, giving near-optimal statistical depth for this study.

\section{Research method}

Grade analysis

In both course elements, grades are given for both individual and group work, running from 1 (lowest) to 10 (best) and typically reported in one decimal. Using suitable weighting factors, these grades are then combined into one final grade for each course. The

\footnotetext{
${ }^{3}$ Namely, plastics injection moulding.

${ }^{4}$ DFMA = Design for Manufacture and Assembly, FMEA = Failure Mode and Effect Analysis. These are common methods used during design engineering to improve product manufacturability and reliability.
} 
weight of the individual work in IP and PO4 is 60 and 40\%, respectively. For the students who participated in $\mathrm{PO} 4$, we analysed these grades, sorting the students into the following three categories:

\begin{tabular}{llll}
\hline & & 2007-2008: 214 students & 2008-2009: 264 students \\
\hline 1 & Did not participate in IP: & 87 students (41\%) & 48 students (18\%) \\
2 & Participated in IP in the same year: & 127 students (59\%) & 203 students (77\%) \\
3 & Participated in IP in the previous year: & n/a & 13 students (5\%) \\
\hline
\end{tabular}

For each category, we determined the average grade that these students achieved for the individual part of PO4 (arithmetic mean values). For practical reasons, we did not analyse the results of the old, more or less comparable courses. The $\sim 6 \%$ students who started PO4 but did not finish it were also excluded.

\section{Student questionnaires}

At the end of PO4, all students were invited to fill in a paper questionnaire, which contained a set of three propositions. Our aim was to determine how they experienced the connection between IP and PO4. Students could indicate their opinions on a five-point scale: 'agree completely', 'agree', 'agree partially', 'disagree' and 'disagree completely'. As a control question, they were also asked to indicate their results for the preceding course IP. The questionnaire was conducted anonymously. The three propositions were:

P1. During IP, I learned sufficiently about common production processes to be able to execute PO4.

$\mathrm{P} 2$. When in PO4 I needed to gather information about new production processes, then thanks to IP I knew how to do that.

P3. The structure for choosing production processes that I learned in IP has helped me in PO4.

These propositions deliberately match the IP core questions as described in "Industrial production (IP)". Furthermore, note that on a higher level of abstraction, they all come down to how theory and practice are linked together in the perception of the students. The filled-in questionnaires were processed using MS Excel.

\section{PO4 staff interviews}

Next to the grade analysis and the student questionnaires, the design coaches of the PO4 teaching staff were interviewed. All are closely aware of the requirements of PO4; also, many of them are well informed of the contents of IP. Via e-mail, they were asked to react to the following propositions:

P1. Students who have participated in IP performed better in PO4 than those who did not, or who took the old courses.

P2. There is a good connection between IP and PO4, also considering the constraints of the bachelor program as a whole. 
In preparing their reactions, the coaches were prompted to refer to the individual PO4 student reports, providing a solid base for their reactions. ${ }^{5}$ Again, opinions could range from 'completely agree' to 'completely disagree'. The answers were compiled using MS Excel. Also, noteworthy remarks were gathered and compiled where relevant.

Note again that the new IDE bachelor program has been introduced all at once, as opposed to normal program revisions, in which old and new program elements are offered simultaneously (allowing second- and third-year students to remain in the old program). Because not all students follow the so-called nominal study path, the PO4 students can be sorted into the categories as mentioned in "Grade analysis". Category (1) can then function as a control group to be compared against the nominal students of category (2), with category (3) providing extra control (see "Discussion"). Finally, note that none of the students self-selected to participate in the new sequence of program elements; rather, they were all enrolled by the faculty in one or two of the elements depending on their individual study history. ${ }^{6}$

\section{Results}

Grade analysis

The results from the grade analysis were as follows (average mark for individual part of PO4, with standard deviation in brackets):

\begin{tabular}{llllrl}
\hline & & $2007-2008$ & \multicolumn{2}{l}{$2008-2009$} \\
\hline 1 & Did not participate in IP: & $41 \%$ & $6.44(1.07)$ & $18 \%$ & $6.25(1.06)$ \\
2 & Participated in IP in the same year: & $59 \%$ & $6.80(0.75)$ & $77 \%$ & $7.02(1.03)$ \\
3 & Participated in IP in the previous year: & n/a & & $5 \%$ & $6.49(0.89)$ \\
\hline
\end{tabular}

A one-sided, independent-samples $t$-test was conducted to compare the PO4 averages for categories 1 and 2. For 2007-2008, the observed 0.36 point difference was found to be significant (p-value: 0.004 ); for 2008-2009, the observed 0.77 point difference was also found to be significant ( $\mathrm{p}$-value: $8.85 \times 10^{-6}$ ). Likewise, the observed 0.53 point difference between categories 1 and 3 in 2008-2009 was found to be significant (p-value $0.029)^{7}$

A one-sided, independent-samples $t$-test was conducted to compare the PO4 averages of categories 2 between both years. The observed 0.22 point difference was found to be significant (p-value of 0.011).

\footnotetext{
${ }_{5}^{5}$ During PO4, the design coaches have intensive contact with individual students (around $1 \mathrm{~h}$ per week per student), which allows them to accurately guide and assess learning outcomes. Written individual reports are also explicitly assessed on several aspects, including those pertaining to production.

${ }^{6}$ Some students were enrolled for both new elements already in 2007-2008, but opted to do IP first and PO4 1 year later, or vice versa. See also footnote \#2.

${ }^{7}$ Considering the small p-values, the slightly more conservative ANOVA comparisons were omitted.
} 
Table 1 Results of the PO4 student questionnaires

\begin{tabular}{|c|c|c|c|c|c|c|c|c|c|c|c|c|}
\hline \multirow[t]{2}{*}{ Proposition } & \multicolumn{6}{|c|}{ 2007-2008: 125 students } & \multicolumn{6}{|c|}{ 2008-2009: 169 students } \\
\hline & $\begin{array}{l}++ \\
(\%)\end{array}$ & $\begin{array}{l}+ \\
(\%)\end{array}$ & $\begin{array}{l} \pm \\
(\%)\end{array}$ & $\begin{array}{l}- \\
(\%)\end{array}$ & $\begin{array}{l}-- \\
(\%)\end{array}$ & $\begin{array}{l}\text { Weighted } \\
\text { average }\end{array}$ & $\begin{array}{l}++ \\
(\%)\end{array}$ & $\begin{array}{l}+ \\
(\%)\end{array}$ & $\begin{array}{l} \pm \\
(\%)\end{array}$ & $\begin{array}{l}- \\
(\%)\end{array}$ & $\begin{array}{l}-- \\
(\%)\end{array}$ & $\begin{array}{l}\text { Weighted } \\
\text { average }\end{array}$ \\
\hline P1 & 25 & 58 & 13 & 5 & 0 & 7.0 & 24 & 56 & 32 & 1 & 0 & 7.1 \\
\hline P2 & 20 & 44 & 24 & 12 & 0 & 6.4 & 8 & 45 & 37 & 9 & 1 & 6.0 \\
\hline P3 & 11 & 46 & 35 & 8 & 0 & 6.2 & 9 & 49 & 30 & 11 & 1 & 6.1 \\
\hline
\end{tabular}

Table 2 Results of the PO4 staff interviews

\begin{tabular}{|c|c|c|c|c|c|c|c|c|c|c|c|c|}
\hline \multirow[t]{2}{*}{ Proposition } & \multicolumn{6}{|c|}{ 2007-2008: eight coaches } & \multicolumn{6}{|c|}{ 2008-2009: fourteen coaches } \\
\hline & ++ & + & \pm & - & -- & Weighted average & ++ & + & \pm & - & -- & Weighted average \\
\hline P1 & 5 & 2 & 1 & 0 & 0 & 8.0 & 6 & 8 & 0 & 0 & 0 & 7.9 \\
\hline P2 & 0 & 4 & 3 & 1 & 0 & 5.8 & 3 & 6 & 3 & 0 & 0 & 7.0 \\
\hline
\end{tabular}

Student questionnaires

In program year 2007-2008, 196 questionnaires were collected, which corresponds to a return rate of $92 \%$. That year, 125 students stated to have participated in IP. In 2008-2009, 178 questionnaires were collected, for a return rate of $67 \%$, and 169 students stated to have participated in IP. The results are given in Table 1.

In this Table, ' ++ ' through '--' mean 'completely agree' through 'completely disagree'. The most common opinion is highlighted in italic: this was always 'agree'. For easy comparison, the Table also presents the weighted averages: the sums of the preceding five columns with weighting factors of 9, 7, 5, 3 and 1 , respectively. ${ }^{8}$ Table 1 reveals that on average, the opinions fall between 'agree' and 'agree partially' for propositions P2-P3, and on 'agree' for P1. The observed difference between both years studied is too small to warrant deeper statistical analysis. ${ }^{9}$

\section{PO4 staff interviews}

In program year 2007-2008, eight of the twelve design coaches responded by giving their opinion of the two propositions. The other four coaches indicated that they were not sufficiently certain as to which theoretical course their students had followed (old or new) to be able to answer. Their opinions could therefore not be included in this research. One year later, fourteen of the eighteen coaches responded to at least one proposition. This time, the others stated they were not sure which students had followed IP prior to PO4. Again, their opinions were therefore not included. The results are given in Table 2 below.

This Table is built up just like Table 1 . As a group, the coaches agree quite strongly with the first proposition, with no significant difference between the 2 years of inquiry. The second proposition was accepted to a higher degree in 2008-2009 than in the previous

\footnotetext{
${ }^{8}$ These particular weighting factors bring the weighted average within the 1-10 scale point used earlier.

9 In program year 2007-2008, we also sent out questionnaires at the start of PO4 to determine the students' expectations, this time with the propositions in their expectant formulations. The weighted averages were 0.2-0.6 points lower, but still positive. For brevity, these results are omitted here.
} 
year, although it was then also quite acceptable. Several remarks were also collected. The most interesting ones were, in no particular order:

(1) The combination of these program elements works excellently!

(2) IP can be improved by giving more attention to the kind of products that PO4 is about.

(3) Students who did IP right before PO4 may outperform the others simply because those others followed the comparable course more than 1 year ago.

(4) IP seems to have taught several theoretical aspects of production very well, but knowledge of practical solutions to common design problems is poor.

(5) Most students appear to be enthusiastic about the combination of these courses.

(6) Some students apply theory (e.g., formulas) blindly and as an end in itself, instead of as a means to improve their design.

We may draw the conclusion that the coaches have the opinion that the designed and enacted course has realized its intentions to a fair extent, although some parts of it can still be improved. In particular, remarks (2) and (4) suggest that the link between theory and practice can and should still be improved; (6) suggests that sometimes, students still fail to see what theory really is for (and not).

\section{Discussion}

Combining the results

In 2007-2008, PO4 students who followed the new course IP in the same year (i.e., category 2) outperformed the ones who followed the old courses (i.e., category 1) by 0.36 points. This is $9.0 \%$ of the effective PO4 grade range, which is between 4.5 and 8.5 ; it was also found to be statistically significant. In 2008-2009, PO4 students who took IP immediately before (i.e., category 2) outperformed the ones who took IP in the previous year (i.e., category 3 ) by 0.53 points; compared to students who did not participate in IP at all (i.e., category 1), they were even 0.77 points better, the difference again showing as statistically significant. IP clearly provides the PO4 students with an advantage. Note that PO4 category 1-students of both years should be compared in a different way: most of those from 2007 to 2008 have had some preparation on the subject of production processes through the old courses, while most of those from 2008 to 2009 have had no such preparation at all. This helps explain the 0.19 point grade difference between these 2 years.

Our questionnaires compliment the picture. On average, the PO4 students consider IP to be a good preparation for the design project; the design coaches agree that IP provides the PO4 students with a clear advantage over the students who followed the old courses. This view is supported by most of the remarks gathered during our staff interviews. Furthermore, the fact that the connection between the two elements seems to have improved over the 2 years suggests that the change made to IP was effective.

We tentatively conclude that the new approach applied in IP and PO4 helps students to apply their theoretical insights into practice, at least more so than in the old program. The educational principles that were adopted perform as expected: feasible for teachers and students alike, motivating ${ }^{10}$ and conducive to the intended results and learning objectives.

${ }^{10}$ In a contest organized by the IDE students association, IP was awarded the students' prize of best new bachelor course for course year 2007-2008 - a rare honour for what used to be an unpopular subject. 
Validity

Clear as these results may seem, several factors force us to be careful. Despite the relatively large number of students, the influence of individuals can still be significant. Since we have found a correlation only and not a causal link, such statistical problems always prevent clear-cut conclusions. Then there are the uncertainties inherent to questionnaires: not all students were reached this way, and the ones who were may have been too burdened with such surveys to be enticed to give very reliable answers. Note that in both years, around $6 \%$ of the students who started PO4 did not finish it; why these students quit is unknown, but it is likely that at least some of them did so because they discovered that they lacked the necessary knowledge, as a result of having missed out on preceding theoretical courses such as IP.

More crucially, at least for 2007-2008 the difference in grades can also be explained by the fact that the old courses were given at least 1 year earlier, as also noted by one PO4 design coach. For 2008-2009, the observed 0.53 difference between the PO4 marks of category (2) and (3) students suggests that much theory can be forgotten in 1 year if it is not applied somewhere during the program before then. This may have been one of the shortcomings of the old program (see "Comparable elements from the old program" and Fig. 2), where there was quite a long time between theory and its application, suggesting that the relative timing of course elements within the program as a whole is perhaps overlooked as a success factor, also in relevant literature.

Finally, there is no guarantee that a student who receives a good (individual) result in PO4 has in fact applied the theory from IP successfully. Designing is an activity that draws upon many fields of knowledge and a wide range of competencies. Likewise, individual grades can never fully correlate with performance in any preceding course. Our results therefore need to be interpreted with caution.

\section{Additional considerations}

Along the way, several observations were made that, although not strictly results of this study, deserve mention because they shed light on the challenges inherent to the new approach and because they may point at new or revised theory. Firstly, creating the new, authentic course material has been intensive and time-consuming. It is hard to find suitable and appealing product examples that lend themselves to meaningful (i.e., non-trivial) application of theory that first- and second-year students can comprehend. Next, presenting them in such a way that $300+$ students indeed see them as examples of the subject matter instead of as the actual course material is another challenge, immediately followed by the complexity of offering mathematics, materials science and structural design in exactly the right order-and all of this in a matrix of teaching modes. Theories on education may have predicted that our approach has potential, but applying it in practice proved-much in the spirit of (Vincenti 1990) — to be very challenging.

Secondly, the new approach implicitly requires a different attitude from teachers. No longer is it sufficient to master one's own theoretical aspect of design engineering: one has to be able to apply this to product design and, crucially, be willing to explain why the theory matters to product design in the first place to students who no longer take this for granted. This takes some staff members, who obviously cannot change their attitude at the flick of a switch, out of their 'comfort zone'. Likewise, to be fully effective, the approach also requires design coaches to get closer to theory. 'Teaching the teachers' appeared to be a critical, but time-consuming success factor. This problem is not new: for instance, in this 
context (Hill 2006) already noted that "changes will especially affect the preparation of technology teachers"; however, in the opinion of the authors, this issue takes on a special urgency because 'ordinary' products make extraordinary demands on theory to explain their behaviour-let alone while they are being designed.

As a final consideration, it bears pointing out that none of the instructional principles adopted in the new bachelor program is new or even unconventional. One may very well wonder why they are not universally adopted. The explanation may lie in the fact that, for reasons such as the observations given directly above as well as the usual barriers to change, not only is it difficult and time-consuming to do so, but also that the real pay-off in terms of e.g., first-time pass rates or other performance indicators does not show quickly. Program revisions such as the one described and studied here therefore require vision, long-lasting management support and confidence. In setting up new programs, this situation is of course different; in this light, it is worth noting that the industrial design programs of Twente University and Eindhoven University have also adopted the theory of constructivism and the ensuing recommendations, as detailed in (Eger et al. 2004) and (Overbeeke et al. 2004), respectively, albeit in quite different ways.

\section{Conclusions and recommendations}

One of innovations of the new TU Delft IDE bachelor program is to help design students bridge the gap between theory and practice. Specifically, it has been configured and implemented in such a way that students learn to apply design engineering theory more effectively and easily during their design projects, letting them realise successful products in every sense of the word. In this study we explored to what extent this new program is successful in this respect, looking closely at one theoretical course and one practical design project, the combination being one that is representative of the problem field.

We conclude that there are strong indications that the new approach is successful in bridging the gap between theory and practice: students and design coaches agree that theory is more easily applied than before, and this is also reflected in the course results and grades. Furthermore, observing the program change as 'reflective practitioners', we experienced how the practical application of knowledge called for new or revised theory. In other words: the bridge that has been built in fact enables two-way traffic. To our knowledge, this represents a breakthrough in thinking about the theory-practice divide that we feel can and should be exploited much stronger. It is also worthy of more academic study than is currently the case.

The new approach was founded on three program design principles that find their base in theories of learning and instruction. The first design principle was: provide an authentic context. Based on the findings we conclude that in the elaboration of the program and in the teaching itself this principle proved to be feasible, although not easy to realise in the start, and provided a strong focus for the activities of students and teachers. The product design process provided a framework for the elaboration of the second design principle: to distinguish explicitly between knowledge, skills and attitude development, and the synthesis of these three elements into strong academic competencies. The content of the courses had to be framed according to the needs of the design process. New content had to be developed and this proved to be possible, although further work will be needed for refining and rejuvenating, keeping the course authentic. The third design principle focused on a chain of activities to do something meaningful and realistic with the theory, and enriching students' understanding through reflection. The findings show that this principle was 
feasible, although the reflection was not easy to realise in the activities of students and teachers. More work has to be done on this issue, preferably by extending the approach in a sequence of activities even more strongly throughout the bachelor program as a whole.

The synthesis of the three design principles (context, content and chain of activities) let to a new approach towards linking theory and practice in design engineering education. The findings show that more refinement and elaboration is possible and necessary, but that the direction of the innovation is already quite promising regarding the overall effectiveness and the satisfaction with students and teachers.

We may also conclude that the research method presented here has been effective and efficient. The combination of grade analysis, student questionnaires and staff interviews gave reliable results, in particular because of the existence of a control group. Moreover, it is feasible in terms of the required time and skills. Therefore, following this method can be recommended to anyone who wishes to analyse the benefits of a program revision, or simply of existing programs. It also yields recommendations that are well-supported in a body of objective facts, providing a firm basis for course assessment and improvement. ${ }^{11}$

Finally, our findings and experiences yield three recommendations on how to link theory and practice during course- or even program revisions, applicable mainly to bachelor-level education in industrial design engineering, but possibly also beyond that.

- Firstly, we recommend using this link as a starting point in new course development and cooperating closely with the relevant staff from other courses, culminating in a serious and successful effort to bring the teaching staff fully up-to-date-not just for the new course itself, but also for the related courses and projects. Put differently, one should not regard the program elements with their respective competency developments as ends in themselves, but as means towards integrated development throughout sequences of elements.

- Secondly, it is recommended to let design students explore important theoretical concepts through practical assignments (experiments, excursions, product analysis etc.) before formalizing them. In such a chain of activities, it is important to focus on theory that is directly relevant to the authentic design problems that are on offer. This last element in particular, we feel, is underestimated in current theory on teaching design engineering in general and industrial design engineering in particular. Everyday products make not-so-everyday demands on the students' capability to understand their functioning and production. Configuring a curriculum with just the right kind and amount of theory, plus sufficient room for its application in authentic tasks, is therefore by no means easy, but feasible and rewarding, as our findings show.

- Thirdly and finally: ensure sound, long-lasting support. Curriculum changes as the one described and studied here inherently require intensive and costly preparation time, largely because of the need to communicate and cooperate closely and intensively, and the need for generating specific course materials. However, the benefits take several years to show. In the opinion of the authors, the vision and management support required to initiate and see through such a change is also underestimated in literature, as witnessed by the apparent absence of e.g., performance indicators or other tools to provide management support.

The activities involving reflection on authentic tasks and the relative timing of theoretical courses and practical projects to one another appear as promising areas for future

11 Teachers may be interested to know that findings such as those presented in "Grade analysis" can also be used to motivate students further (and were in fact used as such by the first author). 
research. Specifically, it can be postulated that during master-level education, the time between theory and application, and back again to theory can be allowed to be longer than during bachelor-level education, to give one follow-up question. Properly studied, this may point the way towards a fourth program design principle.

Open Access This article is distributed under the terms of the Creative Commons Attribution Noncommercial License which permits any noncommercial use, distribution, and reproduction in any medium, provided the original author(s) and source are credited.

\section{References}

Albers, A., Burkhardt, N., \& Ohmer, M. (2004). The constructivist aspect of design education in the Karlsruhe education model for industrial product development KaLeP. In the Proceedings of the 2nd international engineering and product design education conference (pp. 119-126), Sep 2-3 2004. Delft: TU Delft, faculty of Industrial Design Engineering.

Bos, E., Morel, K., Roozenburg, N., Sprangers, M., \& Versteeg, M. (Eds.). (2006). Herziening bachelor IO eindrapport (English: Revision bachelor IDE final report). Delft, The Netherlands: TU Delft, faculty of Industrial Design Engineering.

Bransford, J. D., Brown, A. L., \& Cocking, R. R. (Eds.). (1999). How people learn: Brain, mind experience and school. Washington, DC, USA: National Academy Press.

Christiaans, H., \& Venselaar, V. (2005). Creativity in design engineering and the role of knowledge: Modelling the expert. International Journal of Technology and Design Education, 15(3), 217-236.

Cobb, P. (1994). Where is the mind? Constructivist and sociocultural perspectives on mathematical development. Educational researcher, 23(7), 13-20.

Dym, C. L., Agogino, A. M., Eris, O., Frey, D. D., \& Leifer, L. J. (2005). Engineering design thinking, teaching and learning. Journal of Engineering Education, pp 103-120.

Eger, A., Lutters, D., \& van Houten, F. J. A. M. (2004). 'Create the future': An environment for excellence in teaching future-oriented industrial design engineering. In The Proceedings of the 2nd international engineering and product design education conference (pp. 43-50) 2-3 Sep 2004. Delft: TU Delft, faculty of Industrial Design Engineering.

Hill, R. (2006). New perspectives: Technology teacher education and engineering design. Journal of Industrial Teacher Education, 43(3), 45-63.

Lutgens, G., \& Mulder, M. (2002). Bridging the gap between theory and practice in Dutch vocational education. European Journal of Vocational Training, 25, 34-38.

Nedermeijer, J., \& Pilot, A. (2000). Beroepscompetenties en academische vorming in het hoger onderwijs (English: Professional competencies and academic cultivation in higher education). Groningen, The Netherlands: Wolters-Noordhoff.

Overbeeke, C., Appleby, R., Janssen Reinen, I., \& Vinke, D. (2004). Nine competencies, six units: Industrial design education at TU/e. In the Proceedings of the 2 nd international engineering and product design education conference (pp. 3-10) Sep 2-3 2004. Delft: TU Delft, faculty of Industrial Design Engineering.

Pahl, G., Beitz, W., Feldhusen, J., \& Grote, K.-H. (2007). Engineering design (3rd ed.). London: Springer Verlag.

Pilot, A., \& Bulte, A. M. W. (2006). The use of 'contexts' as a challenge for the chemistry curriculum: Its successes \& the need for further development and understanding. International Journal of Science Education, 28(9), 1087-1112.

Roozenburg, N. F. M. (2008). A competency-based bachelor program for Industrial Design Engineering. In the Proceedings of the 10th engineering and product design education conference, 4-5 Sep 2008. Barcelona, Spain.

Roozenburg, N. F. M., \& Eekels, J. (2005). Product design: Fundamentals and methods. Chichester, UK: Wiley.

Tempelman, E., \& Spoormaker, J. (2010). Educating industrial design engineers in injection moulding and mould construction. In the Proceedings of the TMCE 2010, Apr 12-16 2010. Ancona, Italy (accepted for publication).

Tempelman, E., de Deugd, J. A. G., \& Pilot, A. (2007). Teaching production technology—doing more with less. In the Proceedings of the 5th international conference of the design education forum of Southern Africa, 3-5 Oct 2007. Capetown, Republic of South Africa. 
van der Vegte, W. F., \& van Breemen, E. J. J. (2009). Flowchart-assisted function analysis of products to support teaching of the exact sciences. In the Proceedings of the international conference on engineering design (ICED), 24-27 Aug 2009. Stanford, CA, USA.

van der Vegte, W. F., van Breemen, E. J. J., van Ruijtenbeek, M., Wisse, G., \& van Elderen, E. (2010). 'Products in action': designer-friendly teaching of fundamental engineering topics. In the Proceedings of the TMCE 2010, 12-16 Apr 2010. Ancona, Italy.

Van der Voort, E. J., Heidweiller, A. J., \& Coninx, K. M. (2008). Development of an online coaching tool for mechanics of materials analysis in design projects. In the Proceedings of the 10th engineering and product design education conference, 4-5 Sep 2008. Barcelona, Spain.

Vincenti, W. G. (1990). What engineers know and how they know it: Analytical studies from aeronautical history. Baltimore, MA, USA: John Hopkins University Press.

Walter, R. A. (2002). From the editor-the gap between theory and practice, Journal of Industrial Teacher Education (editorial), 39(4). 